\title{
A Segmented Signal Progression Model for the Modern Streetcar System
}

\author{
Baojie Wang, ${ }^{1,2}$ Wei Wang, ${ }^{1,2}$ Xiaojian $\mathrm{Hu},{ }^{1,2,3}$ and Xiaowei $\mathrm{Li}^{1,2}$ \\ ${ }^{1}$ Jiangsu Key Laboratory of Urban ITS, Southeast University, China \\ ${ }_{2}^{2}$ Jiangsu Province Collaborative Innovation Center of Modern Urban Traffic Technologies, China \\ ${ }^{3}$ Beijing Key Laboratory for Cooperative Vehicle Infrastructure Systems and Safety Control, China \\ Correspondence should be addressed to Xiaojian Hu; huxiaojian@seu.edu.cn
}

Received 10 November 2014; Revised 22 December 2014; Accepted 20 January 2015

Academic Editor: Gualberto Solís-Perales

Copyright (C) 2015 Baojie Wang et al. This is an open access article distributed under the Creative Commons Attribution License, which permits unrestricted use, distribution, and reproduction in any medium, provided the original work is properly cited.

\begin{abstract}
This paper is on the purpose of developing a segmented signal progression model for modern streetcar system. The new method is presented with the following features: (1) the control concept is based on the assumption of only one streetcar line operating along an arterial under a constant headway and no bandwidth demand for streetcar system signal progression; (2) the control unit is defined as a coordinated intersection group associated with several streetcar stations, and the control joints must be streetcar stations; (3) the objective function is built to ensure the two-way streetcar arrival times distributing within the available time of streetcar phase; (4) the available time of streetcar phase is determined by timing schemes, intersection structures, track locations, streetcar speeds, and vehicular accelerations; (5) the streetcar running speed is constant separately whether it is in upstream or downstream route; (6) the streetcar dwell time is preset according to historical data distribution or charging demand. The proposed method is experimentally examined in Hexi New City Streetcar Project in Nanjing, China. In the experimental results, the streetcar system operation and the progression impacts are shown to affect transit and vehicular traffic. The proposed model presents promising outcomes through the design of streetcar system segmented signal progression, in terms of ensuring high streetcar system efficiency and minimizing negative impacts on transit and vehicular traffic.
\end{abstract}

\section{Introduction}

Modern streetcar system is similar to light rail systems and operates along shared or segregated right-of-way. The main difference between light rail and modern streetcar system is the degree of integration into the urban environment and the scale of the associated infrastructure $[1,2]$. Given its potential value as an efficient, energy-saving, environmental, and comfortable urban transit mode, there has been a significant increase in the use of the modern streetcar system in Europe since the late 1990s and is currently fast growing throughout the world. Take China as example; modern streetcar systems in some cities of China, such as Beijing, Shanghai, Tianjin, Suzhou, Shenyang, and Dalian, are already under operation. In addition, more streetcar systems are still under construction in more than 30 other cities. By 2020, China will have built more than 100 modern streetcar lines with the total length of 2,500 kilometers.
Although modern streetcar system is considered as an important mode of urban transit systems in China, it still faces massive challenges in its construction and development due to existing conflicts between the streetcars and other vehicles at the intersection. And these problems are even exacerbated since a growing number of vehicles are on the urban streets, with the rapid urbanization and motorization of China. Table 1 presents a series of evening-peak (16:3018:30) operating data collected from the Shanghai, Tianjin, and Dalian modern streetcar systems between February 24 and March 2, 2014. In this table, dwell time denotes the time a streetcar spends at the station; intersection delay denotes the streetcar deceleration time, stop time, and acceleration time at the intersection; total delay equals a sum of dwell time and intersection delay. The data involves Zhangjiang Streetcar 1\# in Shanghai city (10 km long, 15 stations), Binhai New City Streetcar 1\# in Tianjin city (7.9 km long, 14 stations), Streetcar 201\# (11.6 km, long 19 stations) and Streetcar 202\# 


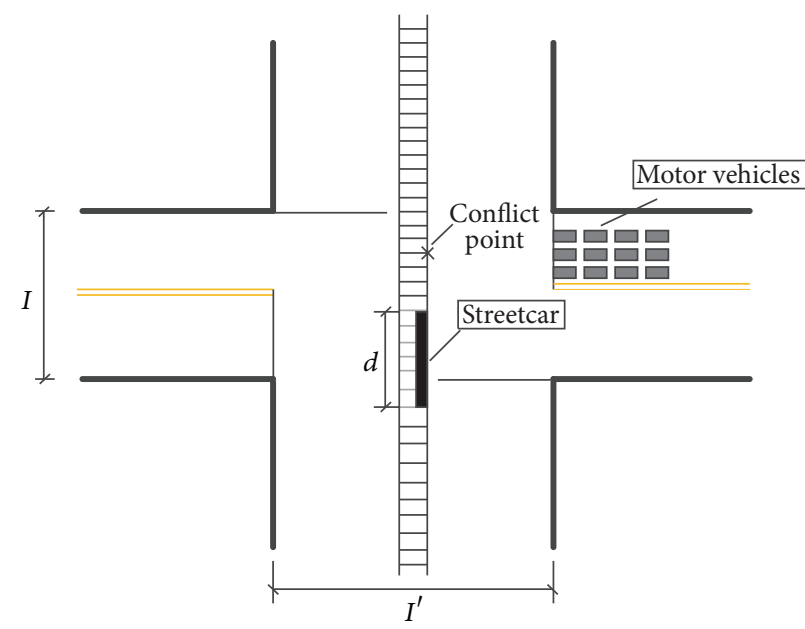

(a) Center lanes

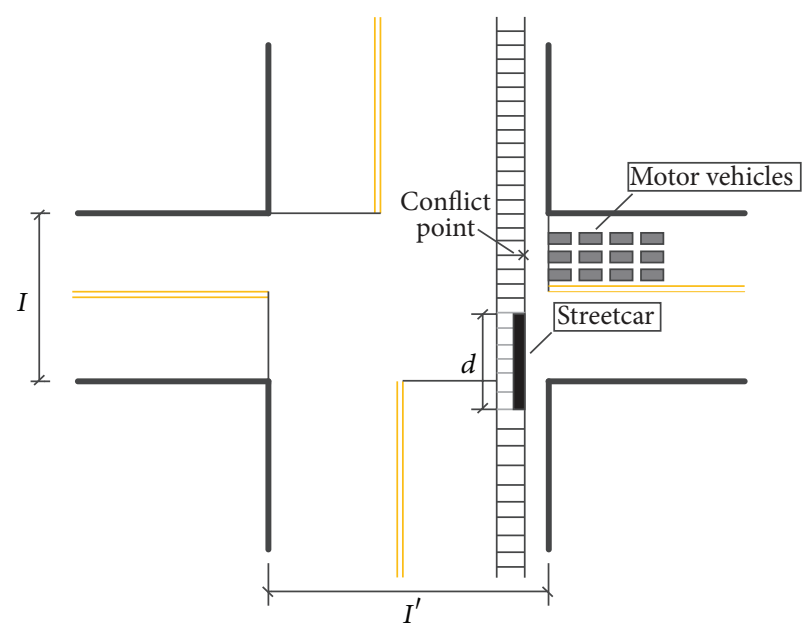

(b) Roadside lanes

FIGURE 1: Track locations of modern streetcar systems.

(12.6 km long, 19 stations) in Dalian city. The data shows a high proportion of delay (23.63\%) and stops (38.25\%) at the intersection.

Hexi New City Streetcar 1\# and Qilin Streetcar 1\# in Nanjing city is the first two off-wire modern streetcar systems of Jiangsu province. Furthermore, Hexi New City Streetcar 1\# is planned to operate on August 1, which is specially prepared for the Second Summer Youth Olympic Games in Nanjing. Aiming at making Hexi New City Streetcar 1\# system more reliable, faster, and cost-effective, Southeast University and Les Information Technology Co., Ltd., are commissioned to study on its priority strategies by Nanjing Department of Transportation. This paper introduces a segmented signal progression methodology for the modern streetcar system in detail.

This paper is organized into six sections. Section one is the introduction which has been discussed above. The next section gives a review of the literature for studies and experiences of streetcar system priority strategies. It is followed by the control framework outlines of the basic control concept, model assumption, design process, and notations adopted. The formulation of the objective function and its constraints are given in the Modeling Methodology. It is followed by the results obtained through microsimulation and the discussion of the results, with preoperating data of Hexi New City Streetcar 1\#. In the last section, the major conclusions of the study and the promising directions of the future research are presented.

\section{Literature Review}

Modern streetcar system is confronted with many challenges, such as poor traveling speeds, unreliability, safety, and difficulties in providing universal access [3]. With the consensus being that Transit Signal Priority (TSP) is identified as a cost-effective way to make on-street transit faster, safer, more reliable, and cost-effective [4], researchers have focused on methodologies of streetcars' signal priority strategy, bunching control, and schedule optimization [5-8]. Some studies have reported the benefits of various practices. The most classic cases of TSP development are in Melbourne, Australia, and Toronto, Canada [3].

In Melbourne, vehicular traffic has impacted streetcar system efficiency to the extent that streetcar speed was in the bottom 20th percentile of system operating speeds for streetcar system services since early this decade. Statistically speaking, the average operating speed of streetcar was merely $15.5 \mathrm{~km} / \mathrm{h}$, compared to $16.8 \mathrm{~km} / \mathrm{h}$ in Brussels, $19.1 \mathrm{~km} / \mathrm{h}$ in Berlin, and $19.3 \mathrm{~km} / \mathrm{h}$ in Prague [9]. The major difference in operational terms between Melbourne's streetcar systems and other international systems is that Melbourne's systems do not provide enough priority for streetcars like the overseas examples. Hence, Melbourne launched two projects to improve the streetcar system efficiency. The main policy initiative is called "Think Tram." The other is called the "Route 109" Project. They both carry out a series of infrastructure improvement projects to achieve a high level of streetcar system service. The projects mainly include hardware facility developing and TSP upgrading [10]. Subsequently, a new generation of TSP is under way, which is called Dynamic Signal Priority (DSP) Project. One advantage of this project is the application of conditional priority control. It makes priority more conditional on the degree of traffic congestion experienced. Another is to resolve competing calls for priority (conflicts) in an intelligent manner. It provides priority in a variable manner dependent on a weighting factor given to each priority call. The weighting factor is determined by the degree of lateness of a streetcar [11].

In Toronto, a Transportation Vision of Toronto Official Plan is focused largely on transit infrastructure investment and transit priority control [12]. To translate the vision statements and principles of potential transit priority benefits into reality and quantity, the 504 King streetcar route in heart of Toronto is chosen as a case study. Four priority schemes are modeled in a microsimulation framework, which includes 


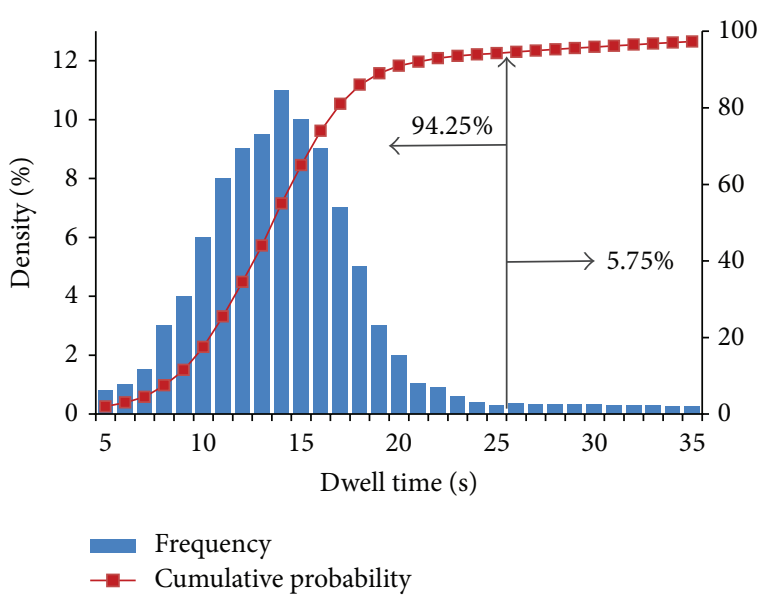

(a) Xuanwumen Station

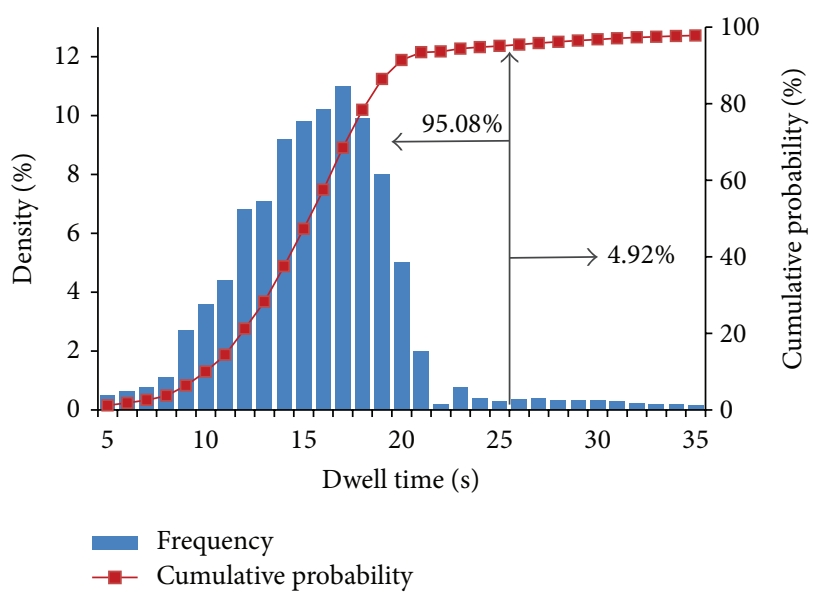

(b) Taiping Beilu Station

FIGURE 2: Distribution of dwell times.

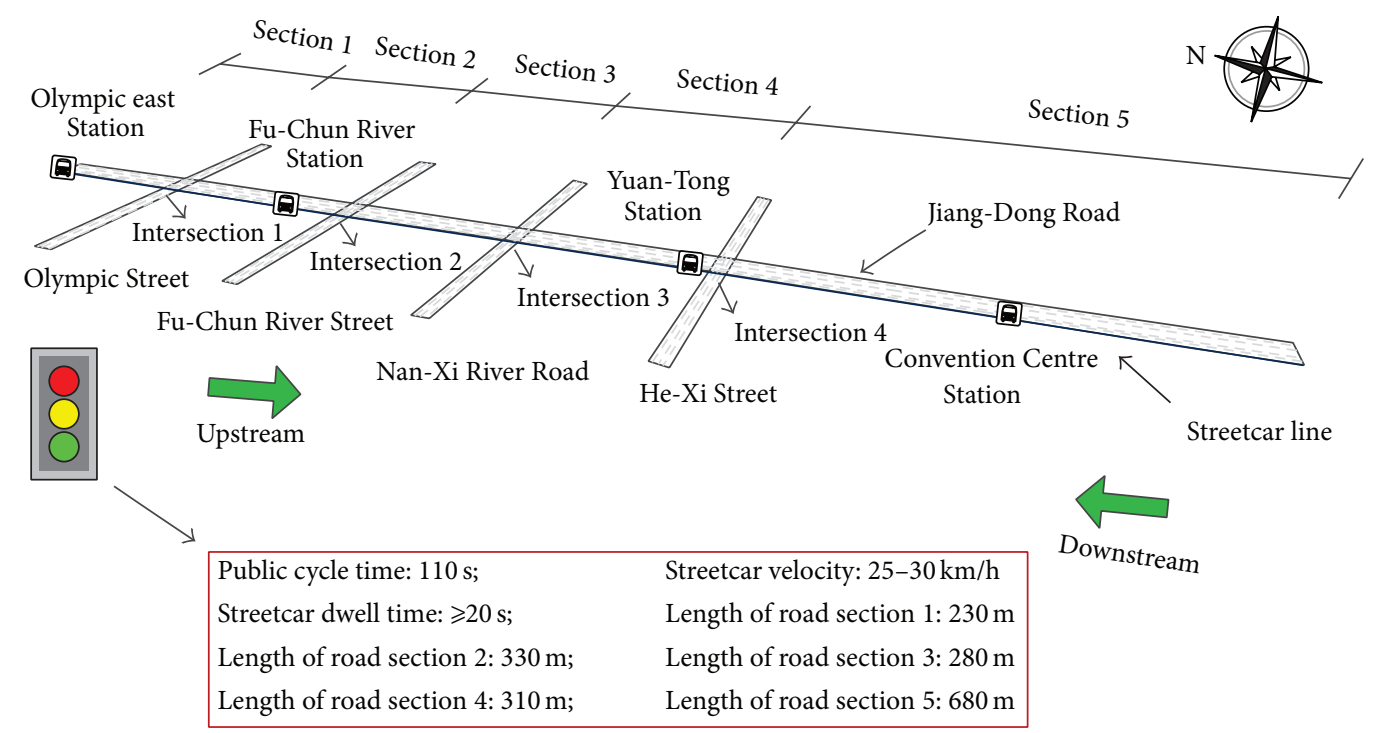

FIGURE 3: Basic layouts of the section.

unconditional signal priority, turning off signal priority, prohibiting all left turns, and finally prohibiting traffic from King Street. The results show that potentially transforming the arterial into a transit mall accessible only to streetcar systems is recommended [13]. Proof-of-Payment and Multiple-Unit streetcar systems operations are investigated by a microscopic traffic simulation model of the 504 King and the 512 St. Clair streetcar routes in Toronto. They display a better performance than Pay-on-Entry and Single-Unit on headway variability, capacity, and operating speed for streetcar systems [14]. The City of Toronto and Toronto Transit Commission confirm the studies and implement an aggressive plan to ensure streetcar system priority. The plan includes Dedicated Right-of-Way, Active Transit Signal Priority, Multiple-Unit Operation, and Proof-of-Payment [15].

In other cities like San Diego and Shanghai, streetcar systems are allocated with median streetcar-only lanes in the segment and provided with passive priority at the intersection. The priority systems share the following features: the lines are set with near-side stations; the signal timing is fixed; the streetcar dwells in station only if its phase is green [16]. The priority systems in the two cities rely on operators' subjective judgments and transfer the intersection delay to the station dwell time.

The studies and practices in Melbourne, Toronto, San Diego, and Shanghai indicate that there are two measures mainly utilized to achieve streetcar system high efficiency. One is the infrastructure development to separate streetcars and motor vehicles to a maximal extent possible. The other is the advancement of TSP algorithms (Figure 1). With these steps, all of the four cities have increased the efficiency of streetcar operations. Particularly in Melbourne and Toronto, they have proved to gain significant progresses of a reduction 


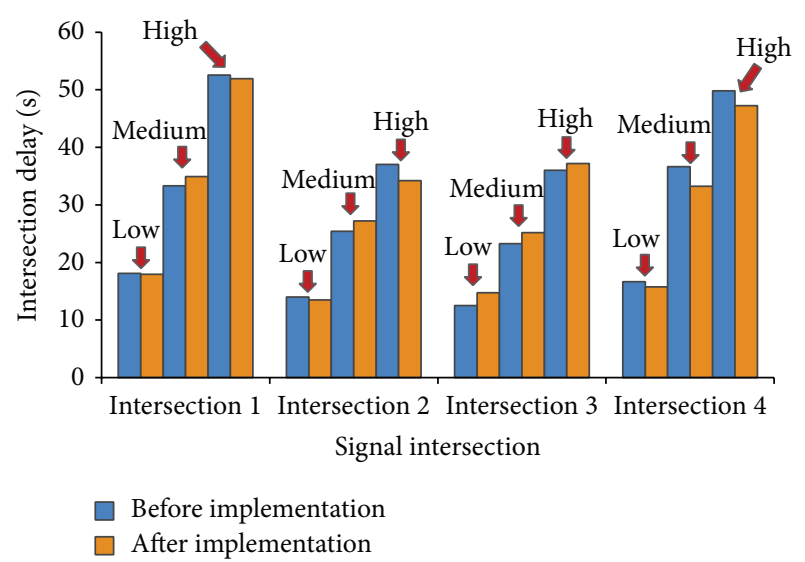

FIgURE 4: Average vehicular delay at intersections under different level of demand.

$(6 \%-10 \%)$ in streetcar travel times [11]. Despite the promising progresses in previous studies, there is still insufficient research on freshly hatched modern streetcar systems. For example, Hexi New City Streetcar 1\#, in the City of Nanjing, is a significant project during the Second Summer Youth Olympic Games. It is allocated with up to date infrastructure, $100 \%$ modern low-floor vehicles, and dedicated right-of-way along the whole route, except intersections. Nevertheless, there is a lack of adequate historic data supplies to support the design of TSP schemes for it, according to the previous methodologies. Now that it is hard to develop an active signal priority strategy, the pressing matter of the moment is to set up a background signal progression scheme for the system. Additionally, there is not enough research on the background signal progression for modern streetcar system. The objective of the study is to propose and demonstrate a methodology of segmented signal progression for the modern streetcar system.

\section{The Control Framework}

\subsection{Basic Control Concept}

3.1.1. Unnecessary to Provide Bandwidth for Streetcar System. Modern streetcar system is an important auxiliary and extension for subway in China. Based on the experience of the completion of some projects in Shanghai, Shenyang, Zhuhai, Shenzhen, Suzhou, and Nanjing, the system costs nearly 25,000,000 USD per kilometer, which is a higher cost compared to other on-street transit systems' cost. Hence, partly for the cost concern, an arterial usually lays only one streetcar line in China. Moreover, it rarely occurs that two or more streetcars arrive at intersection at the same time. Therefore there is no need to provide maximized bandwidth for streetcar systems.

3.1.2. Dividing the Arterial into Several Control Units. The uncertainty of streetcar dwell time is a major cause which troubles the signal progression implementation for modern streetcar system. Specifically, if the arrival time of the streetcar is within a set time period, the streetcar can enjoy progression which has already been set up. And if not, the streetcar cannot enjoy that progression. The arrival time of the streetcar depends on its running speed and dwell time at each station. While the running speed can be guaranteed with streetcaronly lanes, the dwell time is the main factor affecting the actual arrival time of the streetcar deviating from specific time at the intersection. Moreover, the more the number of the stations is, the greater the uncertainties of dwell time will be. And uncertainties of dwell time at each station will be added up to aggravate the arrival time fluctuation. Hence, the arterial for the signal progression implementation should be divided into several control units. The endpoint of each control unit is set up to be an error calibration place for the next control unit.

3.2. Model Assumption. The assumptions of the models in this study are given as follows.

(1) There is only one modern streetcar line operating along an arterial and no other streetcar lines go across it.

(2) All of the intersections are controlled by traffic signals.

(3) Modern streetcar systems are provided with dedicated right-of-way in the segment between two intersections.

(4) There never exists such a situation that two or more vehicles from the same direction arrive at one intersection at the same time.

(5) Streetcar dwell time, like dwell time of on-street transit, follows a certain distribution function.

(6) Dwell time for passenger service or streetcar charging is within passengers' toleration time.

(7) Deceleration and acceleration times are seen as a part of streetcar running time.

(8) For simplicity of elaboration, the start of signal progression time for the segment is set to zero.

By all the assumptions above, the effective construction of a segmented signal progression model for the modern streetcar system can be achieved. And it is allowed to be formulated in a statistical framework.

3.3. Design Process. The specific steps are summarized as below.

(1) Determining the control unit: the control unit usually contains several coordinated intersections associated with no more than 5 streetcar stations. The control joints must be stations. The specific number of intersections and stations is up to managers, depending on their control demand.

(2) Outlining the background signal timing schemes: the background signal timing schemes are set up with Webster method based on vehicular traffic characteristics. Public cycle time of the control unit 


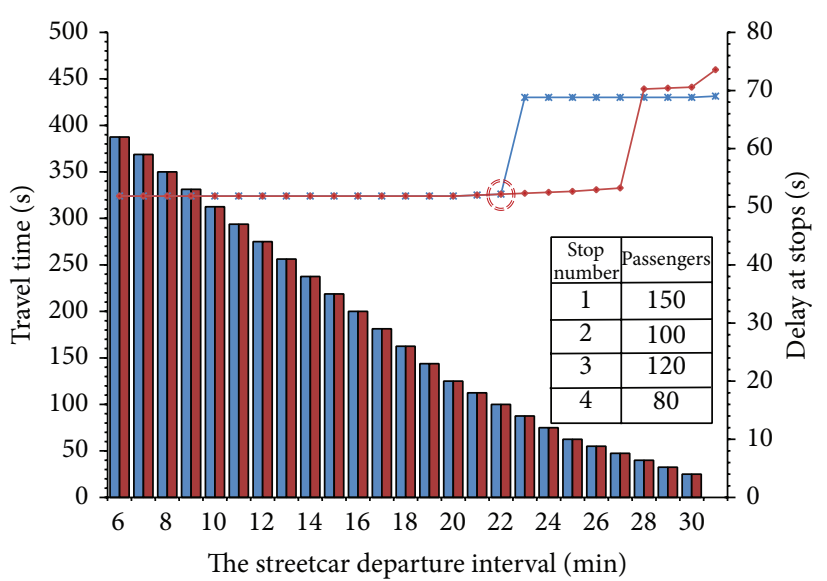

(a) Lower passenger demand

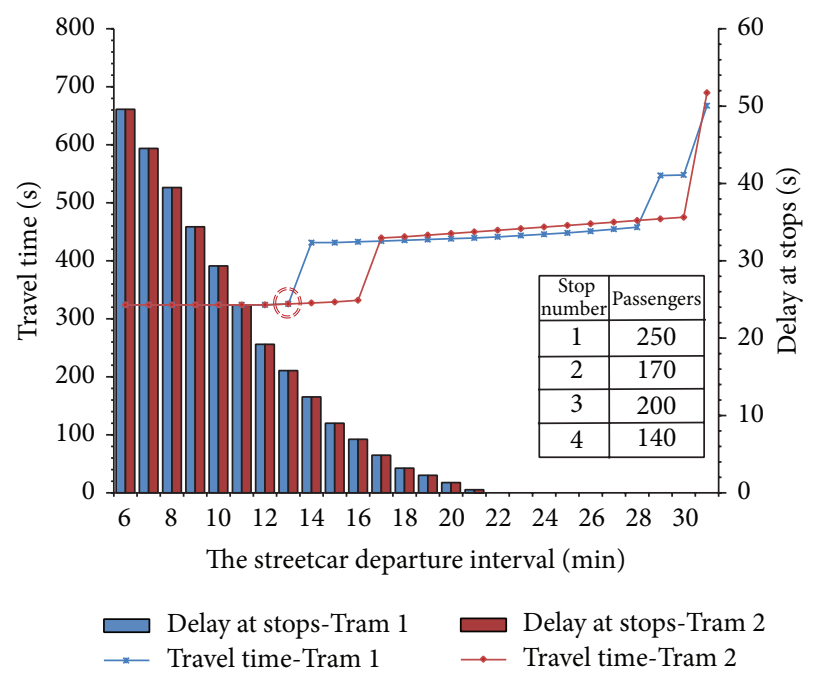

(c) High passenger demand

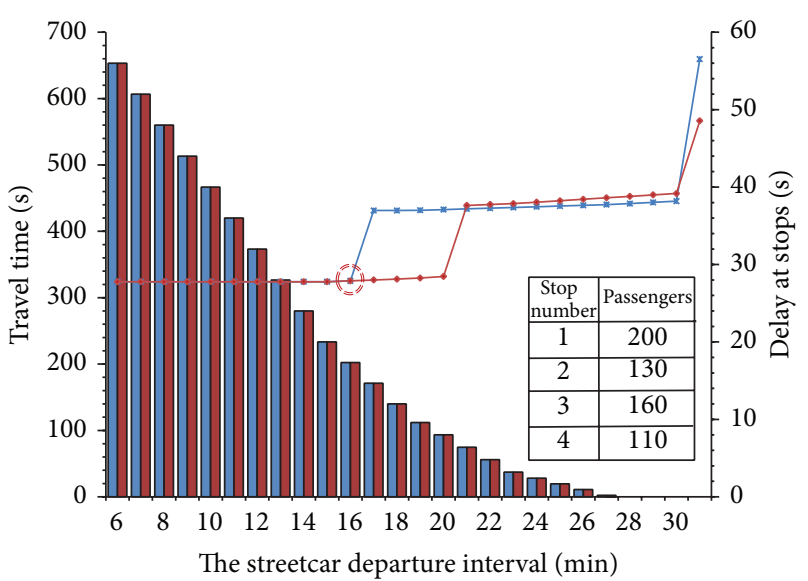

(b) Low passenger demand

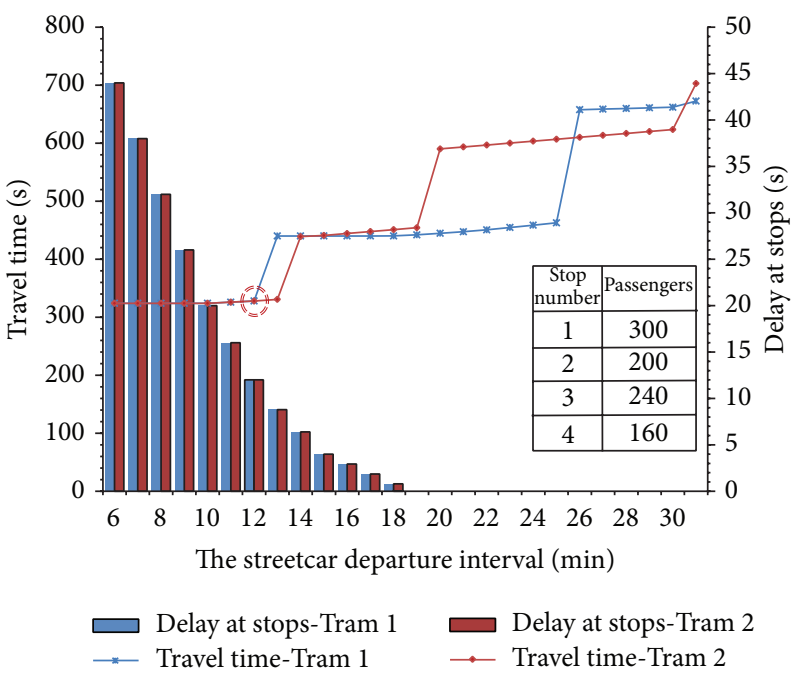

(d) Higher passenger demand

FIGURE 5: Impacts of streetcar departure intervals on streetcar system progression.

is determined by a key intersection, whose traffic demand is the largest or whose position is the most critical.

(3) Building signal progression models: two series of models for upstream and downstream streetcar routes are built separately, which keep a streetcar passing through each intersection at an ideal time.

(4) Defining the constraints: set up constraints for the models, including the signal cycle time constraint, streetcar running speed constraint, available passage time constraint, and dwell time constraint.

(5) Searching for the optimal offsets: search for optimal offsets which satisfy the two-way signal progressions for the streetcar system.

3.4. Notations. The notations used in the model are described below.

$T$ : Public cycle time of the control unit (s)
$G_{\text {allow }}$ : Available time for streetcar passage during the streetcar phase (s)

$Y$ : Yellow time (s)

$L_{i}$ : Length of route section $i(\mathrm{~m})$

$A_{j}$ : Time of an upstream streetcar arriving at intersection $j(\mathrm{~s})$

$\bar{A}_{j}$ : Time of a downstream streetcar arriving at intersection $j(\mathrm{~s})$

$W_{i}$ : Dwell time of an upstream streetcar at station $i(\mathrm{~s})$

$\bar{W}_{i}$ : Dwell time of a downstream streetcar at station $i$ (s)

$V_{\text {up: }}$ Velocity of upstream streetcars $(\mathrm{km} / \mathrm{h})$

$V_{\text {down }}$ : Velocity of downstream streetcars $(\mathrm{km} / \mathrm{h})$

$t_{j, \text { allow/2}}$ : The median of available time for the upstream streetcar passage during a streetcar phase at intersection $j(\mathrm{~s})$ 


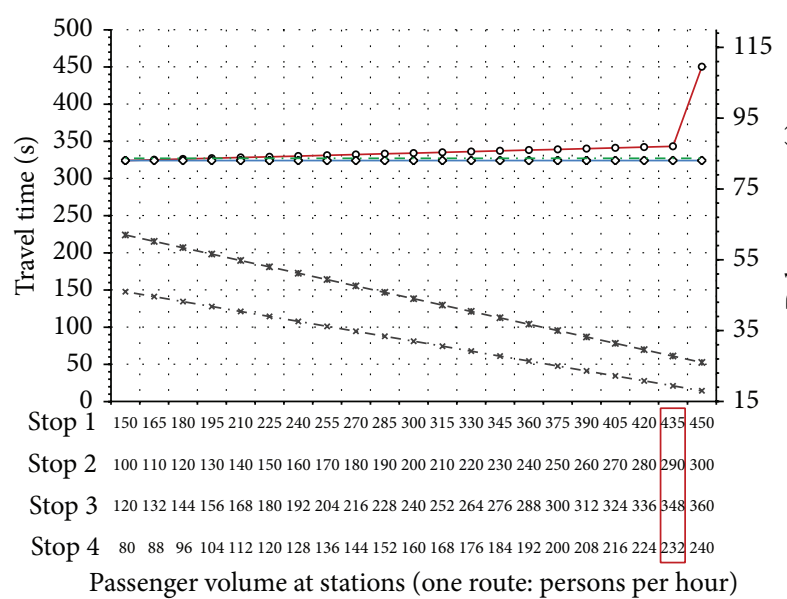

(a) Departure interval (6 minutes)

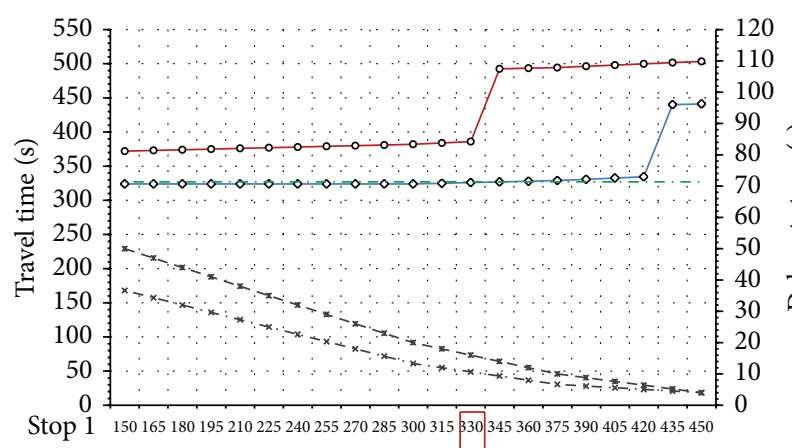

Stop $2100110120130140150160170180190200210 \not 20230240250260270280290300$

Stop 3120132144156168180192204216228240252264276288300312324336348360

Stop 4808896104112120128136144152160168176184192200208216224232240

Passenger volume at stations (one route: persons per hour)

$\begin{array}{ll}\multimap-\text { Travel time-Tram } 1 & -*-\text { Delay at stops-Tram } 1 \\ \multimap-\text { Travel time-Tram 2 } & -\times- \text { Delay at stops-Tram } 2 \\ .-- \text { - Designed travel time } & \end{array}$

(c) Departure interval (10 minutes)

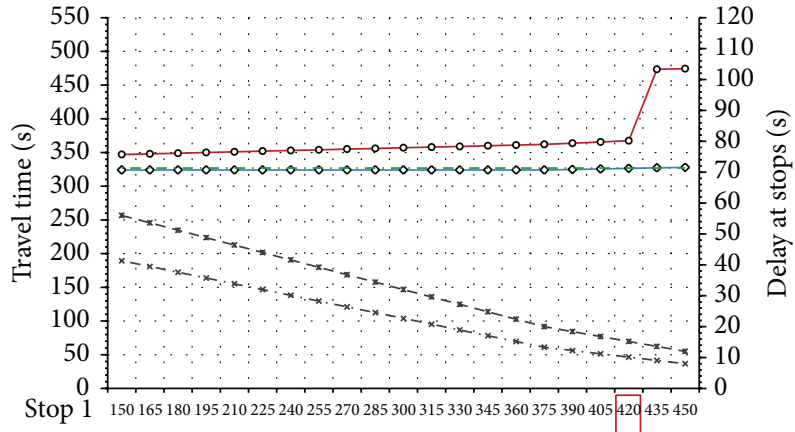

Stop 2100110120130140150160170180190200210220230240250260270280290300

Stop 3120132144156168180192204216228240252264276288300312324336348360

Stop 4808896104112120128136144152160168176184192200208216224232240

Passenger volume at stations (one route: persons per hour)

(b) Departure interval (8 minutes)

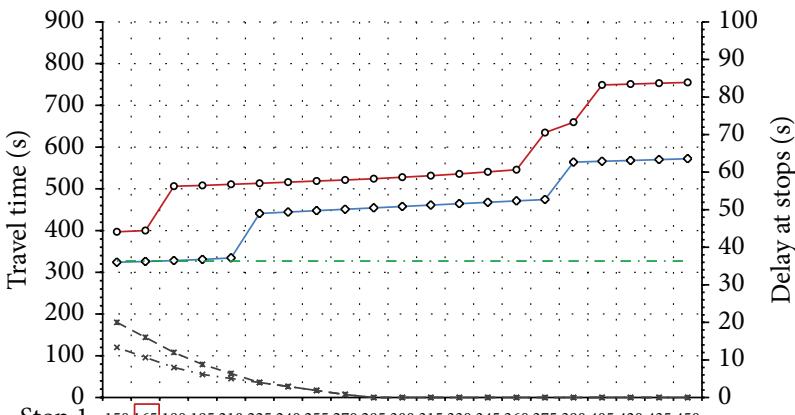

Stop 1150165180195210225240255270285300315330345360375390405420435450

Stop 2100110120130140150160170180190200210220230240250260270280290300

Stop 3120132144156168180192204216228240252264276288300312324336348360

Stop 4808896104112120128136144152160168176184192200208216224232240

Passenger volume at stations (one route: persons per hour)

$\begin{array}{ll}\multimap-\text { Travel time-Tram } 1 & -*-\text { Delay at stops-Tram } 1 \\ \multimap-\text { Travel time-Tram } 2 & -\times- \text { Delay at stops-Tram } 2 \\ -- \text { - Designed travel time } & \end{array}$

(d) Departure interval (20 minutes)

FIGURE 6: Impacts of passenger flows on streetcars progression.

$\bar{t}_{j \text {,allow/2 }}:$ The median of available time for the downstream streetcar passage during a streetcar phase at intersection $j(\mathrm{~s})$

$E_{j}$ : Offset between intersection $j+1$ and intersection $j$ belonging to upstream route (s)

$\bar{E}_{j}$ : Offset between intersection $j+1$ and intersection $j$ belonging to downstream route $(\mathrm{s})$.

\section{Modeling Methodology}

\subsection{Objective Function}

4.1.1. Offsets Calculation for Upstream Streetcar Route. Streetcar running speed in this direction is set up constantly along the segment. The arrival time at each intersection of an upstream streetcar is calculated as follows:

$$
A_{j}=\sum_{i=1}^{k} W_{i}+\frac{3.6 \times \sum_{i=1}^{j} L_{i}}{V_{\text {up }}}
$$

where $k$ is the number of stations belonging to 1 to $j$ road sections and $k \in[1,2, \ldots, n-1] ; n$ is the number of stations belonging to the control unit; $j$ is an integer variable and $j \epsilon$ $[1,2, \ldots, m-1] ; m$ is the number of road sections belonging to the control unit.

In order to make the arrival time of the streetcar at each intersection exactly equal to the median of the available time for streetcar passage, the arrival time is expressed as

$$
A_{j}=t_{j, \text { allow } / 2} .
$$


Subsequently, the relative offset of two adjacent intersections for upstream streetcar route is deduced as

$$
E_{j}=A_{j+1}-A_{j}
$$

4.1.2. Offsets Calculation for Downstream Streetcar Route. Repeat the work above for streetcar attached to the other direction. The arrival time at each intersection of a downstream streetcar is calculated as

$$
\bar{A}_{j}=\sum_{i=k+1}^{n} \bar{W}_{i}+\frac{3.6 \times \sum_{i=j+1}^{m} L_{i}}{V_{\text {down }}} .
$$

Aiming to make the streetcar arrive at each intersection in the median of the available passage time, arrival time in this direction is obtained and expressed as

$$
\bar{A}_{j}=\bar{t}_{j, \text { allow } / 2} \text {. }
$$

Naturally, the relative offset of the two adjacent intersections in this direction is stated as

$$
\bar{E}_{j}=\bar{A}_{j}-\bar{A}_{j+1} .
$$

4.1.3. Offsets Optimization for Two-Way Progressions of Streetcar System. Ideally, a time when both upstream and downstream streetcars arrive at the intersection is expected, which is the median of the available time for streetcar passage in the streetcar phase. If not met, a situation is pursued, when the two-way streetcar arrival times, both, surround the median of available passage time as far as possible. The objective function for the optimal situation is calculated as

$$
\text { Minimize } \sum_{j=1}^{m-2}\left|E_{j} \% T+\bar{E}_{j} \% T-T\right| \text {, }
$$

where $E_{j} \% T$ and $\bar{E}_{j} \% T$ indicate modular arithmetic.

\subsection{Constraints}

4.2.1. Cycle Time Constraint. The background signal timing scheme is developed by Webster method. The public cycle time of the segment is determined by the key intersection, whose traffic demand is the largest or whose position is the most critical. It makes little difference in traffic capacity at the intersection when the public cycle time hovers $\pm 5 \%$. If $T_{\text {min }}$ denotes $0.95 T$ and $T_{\max }$ denotes $1.05 T$, the cycle time constraint is stated as

$$
T_{\min } \leq T \leq T_{\max }
$$

4.2.2. Streetcar Running Speed Constraint. For control convenience and operation comfortableness, the running speed of the streetcar is set as a constant speed in its whole route or at least in its control unit. However, it is unnecessary for upstream and downstream streetcar running speeds to be equal to each other. In this paper, the streetcar running speed is stated as

$$
\begin{gathered}
V_{\min } \leq V_{\text {up }} \leq V_{\text {max }}, \\
\bar{V}_{\text {min }} \leq V_{\text {down }} \leq \bar{V}_{\max } .
\end{gathered}
$$

4.2.3. Available Passage Time Constraint at the Intersection. Vehicle length of modern streetcar is almost more than $20 \mathrm{~m}$. A longer vehicle length means a longer running time for the same journey. If a streetcar enters intersection at the end of the streetcar phase, a conflict with other vehicles from the next phase will occur. Subsequently, a clearance time needs to be considered. So, the streetcar phase should be divided into available passage time and streetcar clearance time to avoid such time conflict. Modern streetcar track locations generally consist of center lanes and roadside lanes, shown as Figure 2. In the two situations, both available passage time and clearance time are different.

If a modern streetcar system is allocated with central lanes, for a given intersection $j$, the time for a streetcar to pass through the intersection can be calculated as

$$
t_{\mathrm{str}}=\frac{3.6 \times(d+I / 2)}{v_{\mathrm{str}}}
$$

where, $v_{\text {str }}$ is the velocity of the streetcar; $d$ is the vehicle length of the streetcar; $I$ is the intersection width along the track.

Time for a vehicular traffic to arrive at the conflict point can be calculated as

$$
t_{\mathrm{veh}}=\sqrt{\frac{2 I^{\prime}}{a_{\mathrm{veh}}}},
$$

where, $a_{\mathrm{veh}}$ is the acceleration of the vehicular traffic; $I^{\prime}$ is the intersection width across the track.

In conclusion, the available passage time for streetcars on central lanes can be shown as follows:

$$
G_{\mathrm{allow}}=G+Y-\left(t_{\mathrm{str}}-t_{\mathrm{veh}}\right),
$$

where $G$ is green time of the streetcar phase.

As to modern streetcar systems on roadside lanes, the time for vehicular traffic to arrive at the conflict point is regarded as zero. The available passage time can be calculated as

$$
G_{\text {allow }}=G+Y-t_{\text {str }} \text {. }
$$

4.2.4. Dwell Time Constraint. Wire-free operation comes to be an important trend for modern streetcar systems. Nice in France has operated two short off-wire segments (435 and $483 \mathrm{~m}$ ) since 2007. Seville of Spain has taken a $450 \mathrm{~m}$ off-wire segment since 2010. Zaragoza began operating with a 2,000 m off-wire segment starting in 2012. Lots of other systems with wire-free operation lines are now under construction, including the First-Hill line in Seattle and several other cities in Europe [2]. Particularly in Nanjing, two modern streetcar systems of Hexi New City Streetcar 1\# and Qilin Streetcar 1\# are both equipped with off-wire vehicles. However, a wirefree line still needs power and corresponding distribution at certain locations for charging purposes. Therefore, the primary dwell time constraint is needed to meet the charging demand.

The dwell time is mainly for passengers' boarding and alighting, which is usually random. Some studies suggest that 
TABLE 1: Average operating data of Shanghai, Tianjin, and Dalian streetcar systems.

\begin{tabular}{lccc}
\hline Measure & Value & Measure & Value \\
\hline Average dwell time & $17.49 \mathrm{~s}$ & Average intersection delay & $21.31 \mathrm{~s}$ \\
Average operating speed & $17.28 \mathrm{~km} / \mathrm{h}$ & Average running speed & $31.47 \mathrm{~km} / \mathrm{h}$ \\
Proportion of dwell time & $35.15 \%$ & Proportion of intersection delay & $64.85 \%$ \\
\hline
\end{tabular}

TABLE 2: Signal progression parameters based on the proposed model.

\begin{tabular}{lcccc}
\hline Signal intersection & Cycle time $(\mathrm{s})$ & Offset $(\mathrm{s})$ & Minimum dwell time & Streetcar running speed (ideal value) \\
\hline Intersection 1 & 110 & 0 & & \\
Intersection 2 & 110 & 55 & $25 \mathrm{~s}$ & $25-30(27) \mathrm{km} / \mathrm{h}$ \\
Intersection 3 & 110 & 110 & & \\
Intersection 4 & 110 & 170 & & \\
\hline
\end{tabular}

the dwell time follow a certain distribution upon most occasions, such as normal distribution, lognormal distribution, and Wakeby distribution [17-19]. A peak exists in dwell time distribution, and the probability tends to be zero on both ends. A large-scale survey in Nanjing City was conducted by School of Transportation Southeast University between May 27 and June 28, 2013. In this survey, we observed the dwell time for passengers' boarding and alighting at twelve stations and then we discovered a common property, which is that 95.33\% dwell times are less than $25 \mathrm{~s}$. Hence, $25 \mathrm{~s}$ is taken as the second dwell time constraint for passenger service. Distributions of the dwell times related to Xuanwumen Station and Taiping Beilu Station are illustrated in Figure 2.

\section{Evaluation and Analysis}

The VISSIM simulation software is further used to evaluate the operational effects of the proposed model. The experimental section is based on the Hexi New City Streetcar $1 \#$.

5.1. Experimental Section. The experimental section is a part of Hexi New City Streetcar 1\# line. It begins from Olympic East Station and ends at Yellow River Station. The section is 1.83 kilometers long, associated with four stations and four signalized intersections, shown as Figure 3. The direction from Olympic East Station to Convention Centre Station is defined as the upstream route with a name of Tram 1, while the direction from Yellow River Station to Olympic East Station is defined as the downstream route named Tram 2.

5.2. Experimental Results and Analysis. In this section, signal lights at intersections are coordinated and controllable with the same cycle time. Since there is a heavy vehicular traffic in Jiang-Dong Road, so, in the direction of Jiang-Dong Road, green time is relatively longer for vehicles passing through the road; thus green time takes up a significant portion of the cycle. And it is long enough to ensure the streetcar passing through the intersection. Furthermore, all turning traffic along Jiang-Dong Road will be forbidden, during a phase with streetcar traveling. As a result, the current background signal timing scheme fits streetcar system well.
Hexi New City Streetcar 1\# is lacking in statistical data of dwell time, for sake of not being operated until August 1 . However, it is clear that 25 seconds are guaranteed for streetcar charging at each station. Therefore, 25 seconds is the only constraint for dwell time. Table 2 shows the cycle time, offsets, and running speed for the streetcar system progression of this studied section, resulting from the proposed model.

5.3. Simulation Based on Analysis. Data is collected on weekdays under fine weather conditions between May 12 and May 30, 2014. Measures of effectiveness including the streetcar travel time, average vehicular delay at the intersection, and average streetcar delay at the station are employed and obtained from VISSIM. Hence, average streetcar delay at the station means a period from the finish time of passenger service to the deserved departure time of streetcar leaving from the station, when passenger service time is less than 25 seconds. Each simulation runs for two hours and an average value of the 10 times' simulation is adopted.

5.3.1. Impact of Streetcar System Progression on Vehicular Traffic. To investigate the impact of the streetcar system progression generated by the proposed model on vehicular traffic, a comparison of vehicular efficiency before and after the project implementation is made.

Figure 4 shows the simulation results for low, medium, and high volume cases. For each case, average delay at the intersection is used to measure the vehicular efficiency. Take the medium volume scenario as example; the average intersection delay before the project implementation is $33.3 \mathrm{~s}$, $25.4 \mathrm{~s}, 23.3 \mathrm{~s}$, and $36.6 \mathrm{~s}$ from intersection 1 to intersection 4 , while it is $34.9 \mathrm{~s}, 26.7 \mathrm{~s}, 24.2 \mathrm{~s}$, and $33.3 \mathrm{~s}$ after the project implementation. The biggest percentage increase in delay of the intersections under the three volume scenarios is $5.12 \%$. It can be concluded that the streetcar system progression has a negligible effect on the delay of vehicular traffic in the three volume cases. That is because of the methodology having no impact on the original timing scheme.

5.3.2. Impact of Streetcar Departure Intervals on Streetcar System Progression. Under a given passenger demand, shorter departure intervals mean less boarding passengers 
and shorter dwell time at the station, while longer departure intervals imply more boarding passengers and longer dwell time. Supposing that the deserved dwell time for passenger service was less than 25 seconds, streetcar delay at the station occurs. However, if the necessary dwell time was much longer than 25 seconds, streetcars cannot enjoy the progression either. Based on Figure 5, it can be concluded that average streetcar delay at the station decreases with the increase of passenger demand and unreliable probability of streetcar travel time. Optimal departure intervals (22 minutes per hour for lower passenger demand, 16 minutes per hour for low passenger demand, 13 minutes per hour for high passenger demand, and 12 minutes per hour for higher passenger demand) decrease from lower passenger demand scenario to higher passenger demand scenario.

5.3.3. Impact of Passenger Volumes on Streetcar System Progression. The impact of passenger volumes on streetcar system progression is shown in Figure 6. Passenger volume determines the dwell time of streetcar at stops, and also the dwell time is the chief factor affecting the application of streetcar progression. When passengers' boarding and alighting time is less than $25 \mathrm{~s}$, the streetcar can enjoy progression, but the delay of streetcar at stops occurs; when passengers' boarding and alighting time is more than $25 \mathrm{~s}$, the streetcar cannot enjoy progression. The simulation analyzes streetcar's delay and travel time at stops under different passenger volumes when the departure interval time is 6 minutes, 8 minutes, 10 minutes, and 20 minutes, respectively. It can be shown that each passenger volume corresponds to an optimal departure interval, and the departure interval decreases with the increase of passenger volumes. If passenger volumes are around this optimal passenger volume, streetcar experiences an ideal travel time with a minimum delay at stops. It also proves that the optimal passenger demand decreases with the increase of streetcar departure interval. For example, in Figure 6, passengers with the volumes 435, 290, 348, and 232 at stops 1,2,3, and 4 correspondingly seem to be the optimal passenger demand when the departure interval is 6 minutes in the streetcar system, while passengers with the volumes $165,110,132$, and 88 at stops $1,2,3$, and 4 correspondingly are the optimal passenger volume when the departure interval is 20 minutes.

\section{Conclusion}

The proposed model in this study provides effective coordinated priority for streetcars. Two features stand out with it. Firstly, it does not adopt the concept of maximized bandwidth, because there seldom exists a situation where a queue of streetcars passes through the intersection. Secondly, it presets a dwell time, during which streetcar charging (such as 25 seconds at least) and passenger services (in 95\% occasions, passenger service time is less than 25 seconds) are satisfied. Furthermore, it has the potential to be used in setting up a background signal progression scheme for the freshly hatched modern streetcar system.
In addition, a big concern for traffic and transit officials is the negative impacts of streetcar system progression on transit and vehicular traffic. Worries are unnecessary, due to the little differences from the original signal timing scheme. It practically indicates little change in the traffic capacity. Besides, analysis shows that the vehicular traffic delays in three volume scenarios, caused by streetcar system progression, are all very small. It can be negligible when compared to the benefits it brings to streetcar systems.

Also, the performance of the streetcar system progression is validated by the case study results. Two conclusions are drawn. One is that each passenger demand is matched with an optimal departure interval. And it decreases with the increase of passenger demand. The other is that the average streetcar delay at the station gets significant, in cases where departure intervals are much shorter than the optimal for a given passenger demand. Likewise, streetcars deviate from the signal progression, when departure intervals are much longer.

In the future, modern streetcar dwell times associated with passenger boarding and alighting characteristics at the station are recommended to be analyzed based on large amounts of statistical data. More extensive numerical experiments and field tests are required to assess the effectiveness and reliability of the proposed model, under various traffic volumes, streetcar passenger demands, streetcar schedules, and so forth. Further priority strategies for modern streetcar system, such as Green Extension, Red Truncation, Phase Insertion, and Phase Rotation, need to be developed, which help to reply stochastic impacts of streetcar running speed and dwell time causing streetcars to deviate from the progression.

\section{Conflict of Interests}

The authors declare that there is no conflict of interests regarding the publication of this paper.

\section{Acknowledgments}

This study is performed as a part of Transit Signal Priority Project in Hexi New City of Nanjing, which is sponsored by Nanjing Department of Transportation. The study is supported by the National High-Tech Research and Development Program of China (no. 2014AA110303). The authors would like to thank Beijing Key Laboratory for Cooperative Vehicle Infrastructure Systems and Safety Control and the senior students from Transportation School of Southeast University for their assistance in data collection.

\section{References}

[1] Transportation Research Board, Transit Capacity and Quality of Service Manual, Transportation Research Board of the National Academies, Washington, DC, USA, 3rd edition, 2013.

[2] American Public Transportation Association, Modern Streetcar Vehicle Guideline, American Public Transportation Association, Washington, DC, USA, 2013. 
[3] G. Currie and A. Shalaby, "Success and challenges in modernizing streetcar systems: experiences in Melbourne, Australia and Toronto, Canada," Transportation Research Record: Journal of the Transportation Research Board, no. 2006, pp. 31-39, 2007.

[4] H. R. Smith, B. Hemily, and M. Ivanovic, Transit Signal Priority (TSP): A Planning and Implementation Handbook, Intelligent Transportation Society of America, Washington, DC, USA, 2005.

[5] K. Ling and A. Shalaby, "A reinforcement learning approach to streetcar bunching control," Journal of Intelligent Transportation Systems, vol. 9, no. 2, pp. 59-68, 2005.

[6] D. Luckerath, O. Ullrich, and E. Speckenmeyer, "Modeling time table based tram traffic," Journal on Developments and Trends in Modelling and Simulation, vol. 22, no. 2, pp. 61-68, 2012.

[7] O. Ullrich, S. Franz, E. Speckenmeyer, and D. Luckerath, "Simulation and optimization of Cologne' s tram schedule," Journal on Developments and Trends in Modelling and Simulation, vol. 22, no. 2, pp. 69-76, 2012.

[8] T. Nagatani, "Dynamical model for retrieval of tram schedule," Physica A: Statistical Mechanics and its Applications, vol. 377, no. 2, pp. 661-671, 2007.

[9] G. Currie, Melbourne Public Transportation Investment: The Why, the What and the Way Forward, Monash University, Melbourne, Australia, 2005.

[10] D. Cliché and S. Reid, "Growing patronage-think tram?" in Proceedings of the International Conference on Competition and Ownership in Land Passenger Transport, University of Sydney, 2007.

[11] G. Currie and A. Shalaby, "Active transit signal priority for streetcars: experience in Melbourne, Australia, and Toronto, Canada," Transportation Research Record, no. 2042, pp. 41-49, 2008.

[12] A Transportation Vision for the City of Toronto Official Plan, Urban Development Services, Toronto, Canada, 2001.

[13] A. Shalaby, B. Abdulhai, and J. Lee, "Assessment of streetcar transit priority options using microsimulation modelling," Canadian Journal of Civil Engineering, vol. 30, no. 6, pp. 10001009, 2003.

[14] A. Shalaby, A. Georgi, K. Ling, J. Sinikas, and A. Salzberg, "Evaluation of proof-of-payment and multiple-unit operation in difference streetcar route configurations," in Proceedings of the 86th Annual Meeting of the Transportation Research Board, Washington, DC, USA, 2007.

[15] G. Gormick, The Streetcar Renaissance: Its Background and Benefits. A Research Report for the St. Clair Avenue Transit Improvements Environmental Assessment Study, 2004.

[16] M. Li, G. Y. Wu, Y. Li, F. Bu, and W.-B. Zhang, "Active signal priority for light rail transit at grade crossings," Transportation Research Record, no. 2035, pp. 141-149, 2007.

[17] S. Guo, Y. Wei, W. Shi, and Y. Xue, "Statistical analysis of buses'stopping time," Journal of Guangxi Normal University: Natural Science Edition, vol. 24, no. 2, pp. 5-9, 2006.

[18] F. Li, Z. Duan, and D. Yang, "Dwell time estimation models for bus rapid transit stations," Journal of Modern Transportation, vol. 20, no. 3, pp. 168-177, 2012.

[19] S. Rashidi and P. Ranjitkar, "Approximation and short-term prediction of bus dwell time using AVL data," Journal of the Eastern Asia Society for Transportation Studies, vol. 10, pp. 12811291, 2013. 


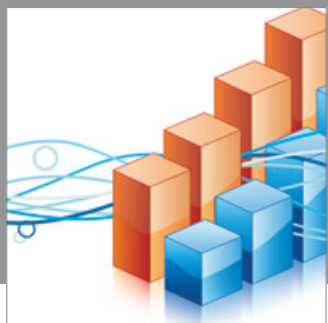

Advances in

Operations Research

mansans

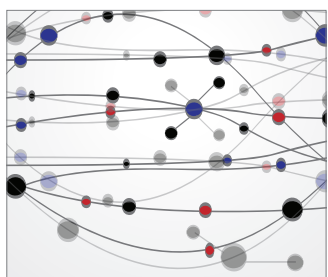

The Scientific World Journal
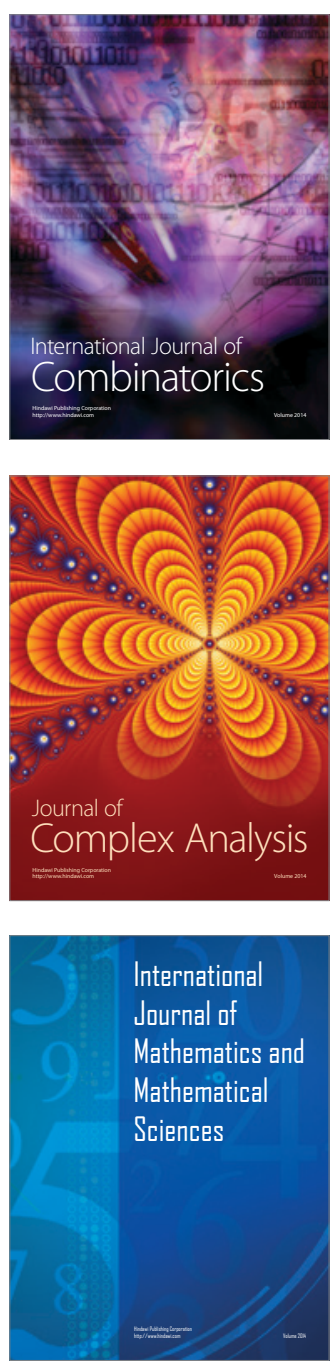
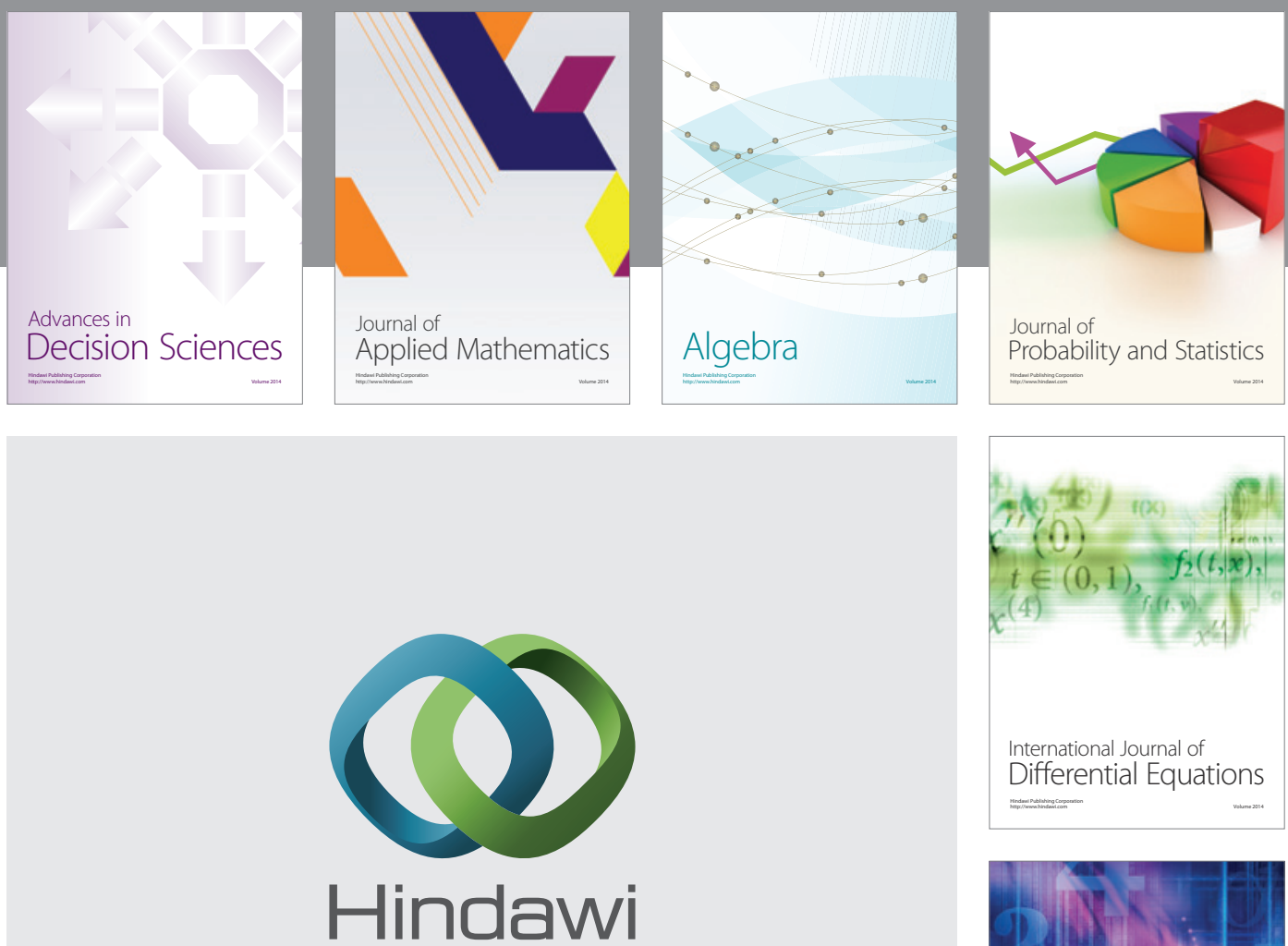

Submit your manuscripts at http://www.hindawi.com
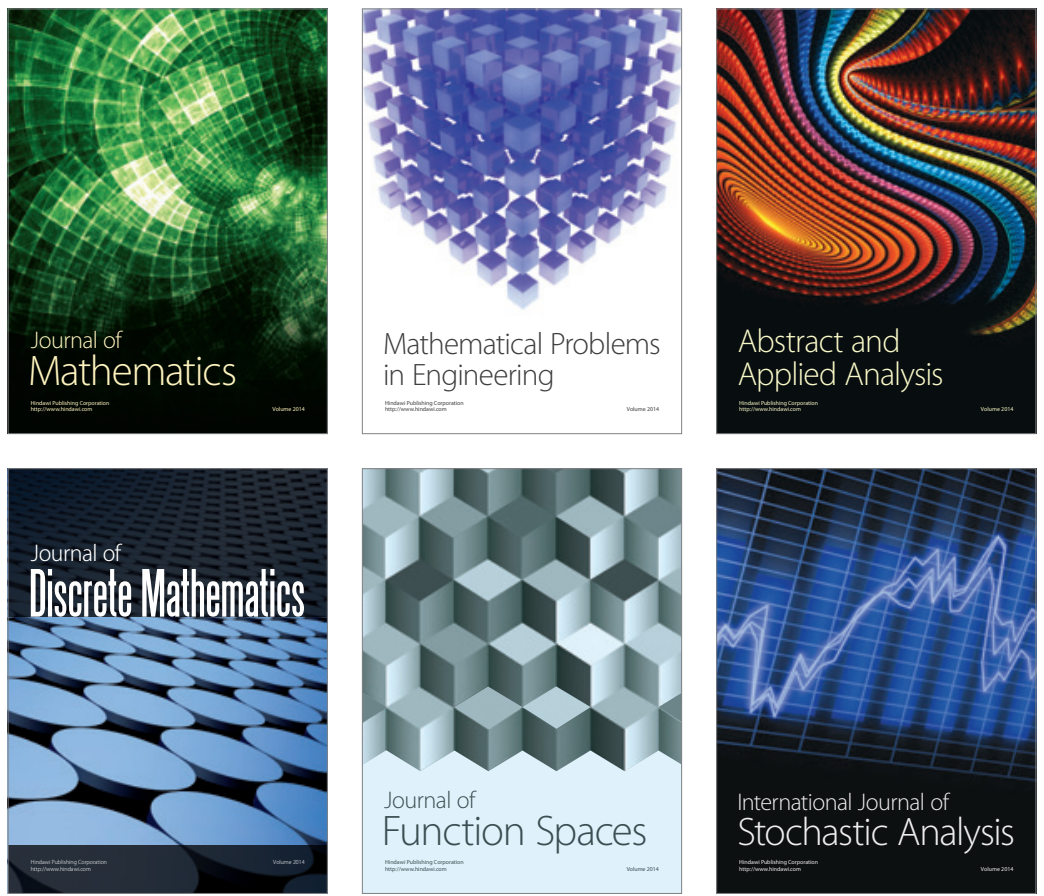

Journal of

Function Spaces

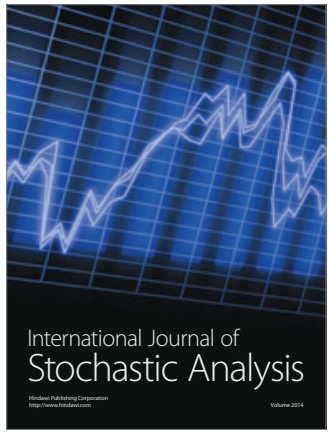

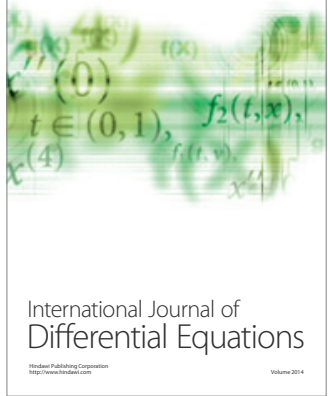
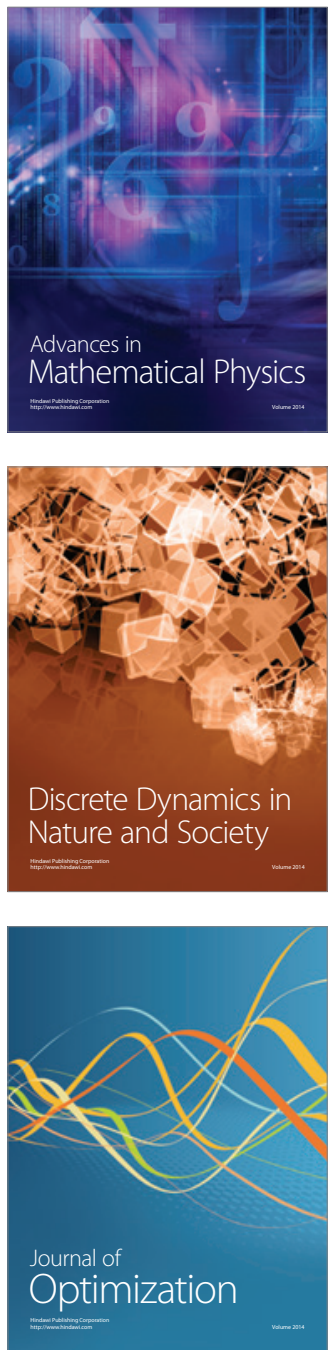